\title{
Lise Öğrencilerine Bilgisayar Donanımı Öğretimi: Devremi Kuruyorum
}

\author{
Birol ÇíLOĞLUGİL $\quad$ Burak Galip ASLAN ${ }^{2} \quad$ Mustafa Murat İNCEOĞLU ${ }^{3}$
}

Geliş Tarihi: 2016-12-09

Kabul Tarihi: 2017-01-02

Öz

$\mathrm{Bu}$ çalışmada, lise öğrencilerinin bilgisayar donanımının temellerini ve ilişskili olduğu matematiksel altyapıyı kavramalarını hedefleyen bir mühendislik farkındalık projesinin yapısı ve sonuçları ortaya konmaktadır. Proje kapsamında temel sayısal elektronik devre tasarımı prensipleri tanıtılmaktadır. Gerçek hayat problemlerinin bir donanım laboratuvarı ortamında öğrencilerin kendi tasarımları ile uygulanması sağlanarak proje içeriği zenginleştirilmiştir. Proje süresince öğrencilerin aktif olduğu tasarım etkinlikleri yardımıyla tecrübe ederek öğrenmeleri yoluna gidilmiştir. Ayrıca, sosyal etkinlik olarak, kampüs yaşamı ve tesislerin tanıtımı için kampüs gezisi ve yaratıcı drama kullanılmıştır. Bunlara ek olarak, proje kapsamında öğrenciler elektronik ve bilgisayar mühendisliği alanları ile ilgili bilgilendirilmiştir. Bu çalışma 35, 10. sınıf öğrencisi ile gerçekleştirilmiştir. Projenin eğitsel bölümü beş günde tamamlanmıştır. Mini sınavlar, günlük sanal sınıf oturumları, mesleki eğilim belirleme cetveli, proje değerlendirme formu, genel değerlendirme oturumu (odak grup görüşmesi) ve veli geribildirimleri proje çıktılarının değerlendirilmesi için kullanılmıştır. Proje ekibinin, öğrencilerin ve velilerin proje ile ilgili olumlu geribildirimleri, önümüzdeki yıllarda bu projenin geliştirilmiş yeni sürümleri üzerinde çalışmak için teşvik edicidir.

Anahtar Sözcükler: Lise mühendislik farkındalık projesi; bilgisayar mühendisliği ve elektronik mühendisliği farkındalık projesi; bilgisayar donanımı ve sayısal tasarım temelleri

1 Arş. Gör. Dr., Ege Üniversitesi, Bilgisayar Mühendisliği Bölümü, birol.ciloglugil@ege.edu.tr

2 Öğr. Gör. Dr., Izmir Yüksek Teknoloji Enstitüsü, Bilgisayar Mühendisliği Bölümü, bgaslan@ieee.org

3 Prof. Dr., Ege Üniversitesi, Bilgisayar ve Öğretim Teknolojileri Eğitimi Bölümü, mustafa.inceoglu@ege.edu.tr 


\title{
Teaching Computer Hardware to High School Students: Building My Circuit
}

Submitted by 2016-12-09

Accepted by 2017-01-02

\begin{abstract}
This paper presents the layout and outcomes of an engineering outreach project that aims to promote insight on high school students towards computer hardware and its mathematical background. Simple circuit design principles have been introduced and the core body of knowledge has been enriched by making students apply their own designs of real-world challenges in a hardware laboratory environment. The students have been assigned to learn by experience with the help of hands-on project design activities during the project. Sightseeing and creative drama have been used as social activities for introducing campus life and facilities. In addition to these, the students have also been informed about digital electronics and computer engineering disciplines within the scope of this project. The project has been conducted with $3510^{\text {th }}$ grade high school students. The educational part of the project has been completed in five days. Quizzes, daily virtual classroom sessions, professional tendency detection scale, project evaluation forms, general discussion (focus group interview) session and parents' feedbacks have been used for the evaluation of the project outcomes. The project personnel's, students' and parents' overall positive feedback about the project have been encouraging for working on enhanced versions of this project in the following years.
\end{abstract}

Keywords: High school engineering outreach project; computer and electronics engineering outreach project; computer hardware and digital design fundamentals 


\section{Giriş}

Bilgi sistemleri ve bilgisayarlar, özellikle yeni milenyumda günlük hayatımızın her alanında yaygınlaşmıştır. Bilgisayarların çoğu, çok çeşitli cihazları kontrol etmek için gömülü sistem mantığıyla çalışmaktadır. Gömülü sistemler, buzdolabı, uydu alıcıları, akıllı telefonlar, yazıcılar gibi tüm elektronik araçlarda bulunmaktadır. Gömülü sistemlerin temel tasarım prensipleri bilgisayar mühendisliği ve elektronik mühendisliği alanlarına dayanmaktadır. Mühendislik alanlarının üniversite eğitimi beklenmeden lise düzeyinde erkenden öğrencilere tanıtılmasının faydaları pek çok çalışmada vurgulanmaktadır (Blair ve Davis, 2013, Smaill, 2010, Watkins ve Swift, 2007). Dolayısıyla, mühendislik farkındalık projeleri, toplumda mühendisliğe yönelik algıyı geliştirerek, lisans düzeyindeki mühendislik dallarının ve bu dalların teorik ve teknolojik temellerinin tanıtılmasını hedeflemektedir.

Mühendislik farkındalık projeleri; bilgisayar mühendisliği, elektrik mühendisliği, elektronik mühendisliği, makine mühendisliği, kimya mühendisliği ve robot bilimi gibi çeşitli mühendislik alanlarına uygulanmıştır. $\mathrm{Bu}$ çalışmada uygulanan mühendislik farkındalık projesi, bilgisayar mühendisliği ve elektronik mühendisliği programlarını hedeflemektedir. Bu nedenle, sadece bu iki alanla ilgili çalışmalar makale kapsamında incelenmiştir.

\section{Alanyazındaki Çalışmalar}

Mühendislik farkındalık projelerinin çoğunun ana amacı STEM (Science, Technology, Engineering, Mathematics - Bilim, Teknoloji, Mühendislik, Matematik) ve özellikle ECE (Electronics and Computer Engineering - Elektronik ve Bilgisayar Mühendisliği) programlarına kayıt olan öğrenci sayılarını arttırmaktır (Blair ve Davis, 2013, Smaill, 2010, Watkins ve Swift, 2007). Bazı çalışmalar yetenekli öğrenciler (Chan ve diğ., 2010) ve Mühendislik alanında Kadınlar (Women in Engineering) programı kapsamında kadınlar (Egbue, Long ve $\mathrm{Ng}$, 2015, Molina-Gaudo, Baldassarri, Villarroya-Gaudo ve Cerezo, 2010) gibi belirli hedef gruplar üzerine odaklanmaktadır.

ECE alanındaki farkındalık projelerinin hedef kitleleri ilkokul, ortaokul ve lise olarak değişebilir. Çoğu çalışma lise öğrencilerini hedeflemektedir (Chan ve diğ., 2010, Molina-Gaudo ve diğ., 2010, Smaill, 2010). İlkokul öğrencileri de sıklıkla çalışılan bir hedef kitlesidir (Cocozza, 2007, Oware, Capobianco ve Diefes-Dux, 2007, Watkins ve Swift, 2007). Bununla birlikte, Watkins ve Swift (2007) erken STEM kariyer başlangıçları için ilgi yaratma ve temel kavramları aşılamak için ilkokulun düzeyinin özellikle önemli olduğunu vurgulamaktadır.

Mühendislik farkındalık projeleri farklı zaman dilimlerinde uygulanabilmektedir. Mehrizi-Sani (2012) çeşitli mühendislik alanlarını hedefleyen ve dört tane birer haftalık ders içeren bir program 
sağlamaktadır. Dördüncü hafta bir tasarım dersi olup, öğrencilerin bu derse katılabilmesi için ilk üç haftaki derslerden en az birisine katılmış olması gerekmektedir. Oware ve diğerleri (2007) her biri bir hafta süren iki alternatif ders içeren bir program önermektedir. Gasser, Lu ve Koh (2010), Ngai, Chan, Cheung ve Lau (2010) ve Thomas, Kruse ve Middlebrook (2012) bir haftalık bir program olarak uygulanmaktayken, Smaill (2010) dört günlük bir program içermekte, Cocozza (2007) ise Kızlar Günü'nde (Girls' Day) uygulanan tek günlük bir program sağlamaktadır.

Farkındalık projelerinin değerlendirme teknikleri de çeşitli değiş̧iklikler göstermektedir. Gasser ve diğerleri (2010) ve Mehrizi-Sani (2012) proje değerlendirme formu kullanırken, Cocozza (2007) ve Egbue ve diğerleri (2015) ön-test ve son-test kullanmaktadır. Bazı çalışmalar ise, öğrencilerin farkındalık projelerine katıldıktan sonra ECE programlarına kayıt olma oranlarının kaydını tutmaktadır (Smaill, 2010).

$\mathrm{Bu}$ çalışmada yapılan mühendislik farkındalık projesi ise, lise öğrencilerinin bilgisayar ve elektronik mühendisliği alanlarındaki ilginç konuları kavraması üzerine odaklanmaktadır. Bunun yanı sıra, proje kapsamında bu alanların basit matematiksel temelleri de öğrencilere tanıtılmaktadır. Dolayısıyla, projenin temel hedefi, öğrencilerin teknolojik gelişmelerle yakından ilgili olan bilgisayar ve elektronik mühendisliği alanlarına olan farkındalıklarını arttırmaktır. Bu bağlamda, projenin amaçları "öğrencilerin teknolojiye olan ilgi ve merakının artmasını sağlamak”, "temel sayısal devrelerin tasarımlarının ve kontrollerinin yapılması konusunda ilgilerini artırmak", “elektronik laboratuvarında deney yapmanın ve çalıştırmanın eğlenceli olduğunu göstermek” ve “temel elektronik ölçüm aletlerinin kullanılmasının öğrenilmesini sağlamak” olarak belirlenmiştir. $\mathrm{Bu}$ farkındalık projesi oldukça ucuza mal edilebilir olduğundan, üniversite laboratuvarlarında yaygın olarak uygulanabilme potansiyeline sahiptir.

\section{Yöntem}

$\mathrm{Bu}$ çalışmada sunulan mühendislik farkındalık projesi, lise düzeyindeki öğrencileri hedefleyen bir haftalık bir program olarak uygulanmıştır. Projenin duyurulması ve ilgili öğrencilerin proje ile ilgili detaylı bilgi sahibi olmasını kolaylaştırmak amacıyla proje için bir web sayfası ile facebook ve twitter sosyal medya hesapları açılmıştır. Projenin web sayfasına aşağıdaki bağlantıdan erişilebilir:

- $\quad$ http://www.devremikuruyorum.ege.edu.tr

Ayrıca, bir YouTube kanalı açılarak, bu çalışma kapsamında laboratuvarda gerçekleştirilecek olan tüm uygulamaların ve devre kurulumlarının adım adım nasıl gerçekleştirilebileceğine ilişkin sunum videoları öğrencilerin kullanımına sunulmuştur. Bu kanala aşağıdaki adres kullanılarak erişilebilir: 
- $\quad$ https://www.youtube.com/channel/UCaOGJrEQyCjAB5QzUTLJrWA

Öğrencilerin öğrenme ortamını zenginleştirmek için, derslerde bilgisayarlar ve projektörler, laboratuvar uygulamalarında deneysel süreci göstermek için doküman kamera ve öğrencilerle velilerinin günlük geribildirimlerini almak için sanal sınıf ortamı gibi teknolojik uygulamalar etkinlikler sırasında kullanılmıştır.

\section{Araştırma Modeli}

Bu çalışmada, lise düzeyindeki öğrencilere yönelik bir mühendislik farkındalık projesi kapsamında nitel ve nicel ölçümler yapılmıştır. Dolayısıyla, bu çalışmada nitel ve nicel ölçümlere dayalı bir tarama modeli kullanılmıştır. Proje süresince veri toplama aracı olarak nicel ölçümler için mini sınavlar, nitel ölçümler için ise, günlük sanal sınıf oturumları, mesleki eğilim belirleme cetveli, proje değerlendirme formu, genel değerlendirme oturumu (odak grup görüşmesi) ve veli geribildirimleri kullanılmıştır. Bu ölçümlerin nasıl yapıldığı ile ilgili ayrıntılı bilgi veri toplama araçları bölümünde ele alınmıştır. Ölçüm sonuçları ise bulgular bölümünde sunulmaktadır.

\section{Katılımcılar (Çalışma Grubu)}

Türk Milli Eğitim Bakanlığı'nın Matematik müfredatı incelediğinde, hazır bulunuşluk düzeyleri açısından 9. sınıfı tamamlayıp 10. sınıfa geçen öğrencilerin bu çalışmanın yürütülmesi açısından en uygun yaş dilimi olduğu görülmüştür. Dolayısıyla, öğrenci seçiminde en az 10. sınıftaki öğrencilerin gönüllü katılımı esas alınmıştır. İzmir’in Bornova İlçesi Milli Eğitim Müdürlüğü ile iletişime geçilerek gönüllü öğrencilerin belirlenmesi sağlanmıştır. Sonuç olarak, ilgili lise öğretmenlerinin de oluruyla, 3 farklı liseden toplam 35 gönüllü öğrenci belirlenmiştir. Çalışmaya 10 kadın ve 25 erkek öğrenci katılmıştır. Çalışmanın 35 öğrenciyle sınırlandırılmasının sebebi; her öğrencinin aynı anda tek başına deneylerini gerçekleştirebileceği, sağlıklı bir laboratuvar ortamını sağlamaktır.

Proje ekibi ise, toplam 4 akademisyenden oluşmaktadır. Teorik derslerin verilmesi için farklı zaman dilimlerinde toplam 3 akademisyen görev yapmıştır. Tüm laboratuvar uygulamalarında ise yine 3 akademisyen takım halinde hazır bulunmuştur.

\section{Veri Toplama Araçları}

Proje kapsamında farklı veri toplama araçları kullanılarak nicel ve nitel ölçümler yapılmıştır. Veri toplama aracı olarak nicel ölçümler için mini sınavlar, nitel ölçümler için ise, günlük sanal sınıf oturumları, mesleki eğilim belirleme cetveli, proje değerlendirme formu, genel değerlendirme oturumu (odak grup görüşmesi) ve veli geribildirimleri kullanılmıştır. Mini sınavlar, projenin ikinci, üçüncü ve dördüncü günlerinde olmak üzere proje süresince toplam üç kez kullanılmıştır. Mini 
sınavlar, teorik dersler sonrasında öğrencilerin bilgi düzeylerini değerlendirmek ve tam olarak öğrenilmeyen kavramları tespit etmek için çok kullanışlıdır (Roediger III, Putnam ve Smith, 2011).

Projenin ilk dört gününde, öğrenciler Ege Üniversitesi bünyesinde İnternet servisi olarak sağlanan sanal sınıf uygulamasına (http://sanalsinif.ege.edu.tr/inceoglu) davet edilerek, ilgili gün için yapılan etkinlikleri her açıdan değerlendirmeleri istenmiştir. Sanal sınıf uygulamaları, projenin ilk dört günü, saat 19:00 ile 20:00 arasında yapılmış olup, arşiv kayıtlarına aşağıdaki linklerden erişilebilir:

- http://sanalsinif.ege.edu.tr/p74mx38gqy9/ (Birinci gün)

- http://sanalsinif.ege.edu.tr/p2vuyf8r20o/ (İkinci gün)

- $\quad$ http://sanalsinif.ege.edu.tr/p6bxa7c7ntt/ (Üçüncü gün)

- $\quad$ http://sanalsinif.ege.edu.tr/p91rauqabuv/ (Dördüncü gün)

Projenin beşinci gününde öğrencilerin mesleki eğilimleri hakkında fikir sahibi olabilmeleri için Milli Eğitim Bakanlığı tarafından önerilen bir mesleki eğilim belirleme cetveli (Mesleki Eğilim Belirleme Cetveli, 2013) kullanılmıştır. Mesleki eğilim belirleme cetveli, 10 meslek kategorisinin her biri ile ilgili 16 madde olmak üzere, toplam 160 madde içermektedir. Öğrenciler hangi mesleğe eğilimleri olduğunu belirlemek için kendilerine yöneltilen test maddelerinden ilgilerini çekenleri işaretlemişlerdir. Bu cetvele ilişsin sonuçlar bulgular bölümünde ele alınmaktadır.

Ayrıca, projenin son gününde, öğrencilerin yürütülen proje ile ilgili görüşlerini almak için proje değerlendirme formunu doldurmaları istenmiştir. Daha sonra, projenin genel olarak değerlendirildiği odak grup görüşmesi niteliğinde bir oturum düzenlenmiş ve tüm öğrencilere söz verilerek geribildirimleri alınmıştır. Proje kapsamında alınan kayıtlar için öğrencilerden projenin ilk günü toplanan veli onay formları ile izin alınmıştır.

Odak grup görüşmesi (Krueger ve Casey, 2002) nitel bir bilgi toplama aracı olup, proje sonunda daha sonra analiz edilmek üzere 75 dakikalık bir video çekimi kaydı yapılması ile gerçekleştirilmiştir. Öğrenciler için bir açık tartışma ortamı sağlamak amacıyla bu farkındalık projesinin pek çok boyutu hakkında gerekli sorular daha önceden hazırlanmıştır. Her öğrenciye proje süresince karşılaştıkları her türlü konu ile ilgili geribildirim verebilmeleri amacıyla konuşabilmeleri için pek çok kez dönüşümlü olarak söz hakkı verilmiştir. Sonuç olarak, hem grup bazında, hem de bireysel bazda öğrencilerden geribildirim almak mümkün olmuştur.

Proje çıktıları öğrencilerin, velilerin ve proje ekibinin bakış açılarına göre analiz edilmiştir. Bu kapsamda, velilerin geribildirimleri analiz sürecine dahil edilmiştir. Bu yaklaşım Chan ve diğerleri (2010) ve Molina-Gaudo ve diğerleri (2010) gibi çalışmalarda da başarıyla kullanılmıştır. Veliler 
proje süresince anlık mesajlarla bilgilendirilmiş ve sanal sınıf etkinliklerinin takip etmeleri için teşvik edilmiştir. Ayrıca, öğrencilerin proje sürecindeki gelişimleri ile ilgili velilerin geribildirimleri alınarak değerlendirilmiştir.

\section{Uygulama Süreci}

Projenin öğrencilerle birlikte uygulanan eğitsel bölümü beş günde tamamlanmıştır. Proje kapsamındaki tüm etkinliklerin ve ilintili değerlendirme süreçlerinin gün bazında dökümleri Tablo 1'de gösterilmektedir. Ayrıca, projenin uygulama süreci gün bazlı olarak ilerleyen alt bölümlerde ele alınmaktadır.

Tablo 1. Haftalık proje planı

\begin{tabular}{|c|c|c|c|c|c|}
\hline & 1. Gün & 2. Gün & 3. Gün & 4. Gün & 5. Gün \\
\hline \multirow[b]{2}{*}{ Sabah } & $\begin{array}{c}\text { Tanışma ve } \\
\text { yaratıcı } \\
\text { drama } \\
\text { etkinliği }\end{array}$ & $\begin{array}{l}\text { Ders: ikili } \\
\text { say1 sistemi } \\
\text { temelleri }\end{array}$ & $\begin{array}{l}\text { Ders: minterm } \\
\text { gösterimi }\end{array}$ & $\begin{array}{c}\text { Ders: } \\
\text { aritmetik } \\
\text { devrelerin } \\
\text { temelleri }\end{array}$ & $\begin{array}{c}\text { Ders: bilgisayar } \\
\text { donanımının } \\
\text { temelleri }\end{array}$ \\
\hline & $\begin{array}{l}\text { Ders: say1 } \\
\text { sistemleri }\end{array}$ & $\begin{array}{l}\text { Ders: ikili } \\
\text { sayı sistemi } \\
\text { temelleri (+ } \\
\text { Mini sinav 1) }\end{array}$ & $\begin{array}{l}\text { Ders: kapı } \\
\text { düzeyinde } \\
\text { minimizasyon } \\
\text { (+ Mini sınav } \\
\text { 2) }\end{array}$ & $\begin{array}{l}\text { Ders: } \\
\text { aritmetik } \\
\text { devrelerin } \\
\text { temelleri } \\
\text { (+ Mini } \\
\text { sinav 3) }\end{array}$ & $\begin{array}{l}\text { Laboratuvar: } \\
\text { osiloskop ve } \\
\text { sinyal üreteci } \\
\text { kullanımı }\end{array}$ \\
\hline \multirow{2}{*}{$\begin{array}{l}\text { Öğlede } \\
\text { n Sonra }\end{array}$} & $\begin{array}{l}\text { Kampüs } \\
\text { yürüyüşü ve } \\
\text { teknopark } \\
\text { gezisi }\end{array}$ & $\begin{array}{c}\text { Laboratuvar: } \\
\text { multimetre } \\
\text { kullanarak } \\
\text { temel devre } \\
\text { elemanı } \\
\text { ölçümleri }\end{array}$ & $\begin{array}{c}\text { Laboratuvar: } \\
\text { yarım- } \\
\text { toplayıcı } \\
\text { devresi }\end{array}$ & $\begin{array}{c}\text { Laboratuvar: } \\
\text { tam-toplayıcı } \\
\text { ve tam- } \\
\text { çıarıcı } \\
\text { devreleri }\end{array}$ & $\begin{array}{c}\text { Genel } \\
\text { değerlendirme } \\
\text { oturumu (+ } \\
\text { Proje } \\
\text { Değerlendirme } \\
\text { Formu) }\end{array}$ \\
\hline & $\begin{array}{l}\text { Girişimcilik, } \\
\text { bilgisayar } \\
\text { mühendisliği } \\
\text { ve elektronik } \\
\text { mühendisliği } \\
\text { seminerleri }\end{array}$ & 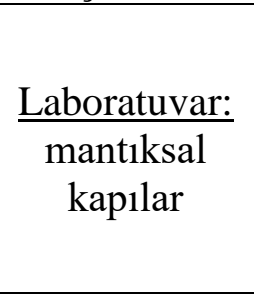 & $\begin{array}{c}\text { Laboratuvar: } \\
\text { yarım-çıarıacı } \\
\text { devresi }\end{array}$ & $\begin{array}{c}\text { Laboratuvar: } \\
\text { tek-bit çarpıc1 } \\
\text { ve bölücü } \\
\text { devreleri }\end{array}$ & $\begin{array}{l}\text { Kapanış töreni } \\
\text { etkinlikleri }\end{array}$ \\
\hline Akşam & \multicolumn{4}{|c|}{ Sanal Sınıf etkinliği } & - \\
\hline
\end{tabular}

Birinci gün. İlk günün sabah oturumu bilgisayar mühendisliği bölümünde düzenlenen açllıs töreni ve açılış konuşmalarıyla başlamıştır. Yaratıcı drama uzmanı bir akademisyen tarafindan gerçekleştirilen buz kırma etkinliğiyle, proje ekibi ve öğrencilerin birbirleriyle tanışmaları sağlanmıştır. Daha sonra, proje kapsamında düzenlenecek tüm etkinliklerle ilgili velilerin 
onaylarının alındığı veli onay formları tüm öğrencilerden toplanmıştır. Ardından, laboratuvar ortamına geçilerek laboratuvarda uyulması gereken güvenlik kuralları öğrencilere aktarılmış ve deneyler sırasında kullanılacak malzemeler öğrencilere teslim edilmiştir. Öğleden sonra sayı sistemleri konusunu kapsayan ilk ders işlenmiştir. Ders sonrasında öğrencilerle birlikte kampüs yürüyüşü gerçekleştirilerek yol boyunca karşılaşılan mekanlar öğrencilere tanıtılmıştır. Yürüyüş, Ege Üniversitesi Teknoloji Transfer Ofisi'nde (EBİLTEM) son bulmuş ve burada öğrencilere girişimcilik ve patentler, bilgisayar mühendisliği ve elektronik mühendisliği konularında seminerler verilmiştir.

İkinci gün. İkili aritmetik ve Boolean mantığın anlatıldığı sabah oturumunda 10 soruluk bir çoktan seçmeli mini sınav uygulanmıştır. Öğleden sonra öğrenciler laboratuvar çalışmalarına başlamışlardır. Elektronik malzemelerin test edilmesi, renk kodları kullanılarak direnç değerlerlerinin okunması, multimetre yardımıyla akım ve gerilim ölçümleri ve temel mantıksal kapıların breadboard üzerine yerleştirilmesi ile ilgili uygulamalar yapılmıştır.

Üçüncü gün. Sabah oturumunda mantıksal fonksiyonların minterm gösterimleri, kapı düzeyinde minimizasyon ve temel aritmetik devre tasarımları konusunda dersler işlenmiştir. Dersler sonunda ise, yine 10 soruluk bir çoktan seçmeli mini sınav uygulanmıştır. Öğleden sonra öğrenciler laboratuvara geçerek çalışmalarına yarım-toplayıcı ve yarım-çıkarıcı devreleriyle devam etmişlerdir.

Dördüncü gün. Sabah oturumunda aritmetik devrelere odaklanan teorik derslere yer verilmiştir. Önceki akşam gerçekleştirilen sanal sınıf oturumunda öğrencilerden gelen geribildirimler dikkate alınarak, teorik konuları gerçek hayata yönelik eğlenceli uygulamalarla zenginleştirmek amacıyla iki oyun benzeri sistem tasarımı örneğine yer verilmiştir. Tasarlanan uygulamalardan birisi iki kişi ile oynanan taş-kağıt-makas oyunu, diğeri ise dört kişinin sonraki Cuma gecesi nereye gideceğine karar vermek için kullandığı bir oylama sistemidir (gruptaki bazı kişiler daha popüler olduğundan iki oy hakkına sahiptir). Her iki örneğin çözümü kombinasyonel devre olarak derste yapılmıştır. Öğrencilerden hemen olumlu geribildirim alınmış olup, teorik dersler ve izleyen laboratuvar oturumları süresinde öğrencilerin motivasyon düzeylerinin arttığı gözlenmiştir. Sabah oturumunun sonunda 10 sorudan oluşan çoktan seçmeli bir mini sınav yapılmıştır. Öğleden sonra ise, öğrenciler tam-toplayıcı, tam-çıkarıcı, tek bitlik çarpıcı ve bölücü devrelerini tasarlayıp laboratuvar ortamında kurmuşlardır.

Beşinci gün. Sabah oturumunda önce mikrobilgisayarların temelleri üzerine teorik bir ders yapılmış, arkasından ise daha önceki günlerde yapılan mini sınavlarda sorulan toplam 30 soru 
çözülmüştür. Laboratuvar çalışmalarının başından itibaren öğrenciler laboratuvardaki osiloskop ve sinyal üreteci gibi diğer donanımlarla ilgili meraklarını dile getirip bu cihazları kullanmak istediklerini söylemişlerdir. $\mathrm{Bu}$ nedenle, tüm teorik ve pratik etkinliklerin başarıyla tamamlanmasının ardından, öğrencilerin meraklarını gidermek adına proje takvimine fazladan bir laboratuvar oturumu eklenmiştir. Bu oturumda öğrencilere osiloskop ve sinyal üreteci kullanımı gösterilmiş ve öğrencilerden bu cihazları kullanmaktan memnun olduklarına dair olumlu geribildirimler alınmıştır. Öğleden sonra, tüm proje ekibi ve öğrencilerin katılımı ile odak grup görüşmesi niteliğinde bir genel değerlendirme oturumu gerçekleştirilmiştir. Daha sonra ise, kapanış töreni ile proje tamamlanmıştır.

\section{Bulgular}

Projenin ikinci, üçüncü ve dördüncü günlerinde mini sınavlar, ilk dört gününde sanal sınıf oturumları, beşinci ve son gününde ise, mesleki eğilim belirleme cetveli ile tüm proje sürecinin değerlendirildiği proje değerlendirme formu ve odak grup görüşmesi uygulanmıştır. Kullanılan bu veri toplama araçlarından elde edilen bulgular ilerleyen alt bölümlerde ayrı ayrı ele alınmakta ve son olarak gözlemler bölümünde projeye ilişkin genel izlenimler paylaşılmaktadır.

\section{Mini Sınavların Sonuçları}

Projenin ikinci, üçüncü ve dördüncü günlerinin sabah oturumlarında teorik derslerin tamamlanmasını takiben öğrencilerden bir mini sınavı yanıtlamaları istenmiştir. Dört seçenekli 10 sorudan oluşan mini sınavların değerlendirmesi, sadece doğru yanıtlar dikkate alınarak (+1 puan) yapılmış, yanlış yanıtlar ve boş bırakılan sorular 0 puan olarak değerlendirilmiştir. Mini sınavlar için öğrencilere mini sınav başına 10 dakika süre verilmiştir. Mini sınavlardaki sorular temel düzeyde olmalarına rağmen, derslerde anlatılan bilgilerin lise öğrencilerine yabancı olacağ düşünüldügünde, öğleden sonra yapılacak olan laboratuvar uygulamalarına hazırbulunuşluk açısından işlenen konuları bireysel olarak gözden geçirme imkanı sunmaktadır.

Projenin ikinci günü uygulanan mini sınava 32 öğrenci katılmıştır. Öğrencilerin 10 sorunun yaklaşık 9 tanesini doğru yanıtladıkları görülmüştür. Başarı oranının en düşük olduğu soru, gri kodlama ile ilgili olan ve \%71.8 oranında doğru yanıt verilen soru olarak tespit edilmiştir. İkili sayı sisteminde toplama ve çıkarma işlemleri ile ilgili olan iki soru ise, tüm öğrenciler tarafından doğru yanıtlanmıştır.

Projenin üçüncü gününde yapılan mini sınava 33 öğrenci katılmıştır. Öğrencilerin 10 sorudaki doğru yanıt ortalamaları yaklaşık dokuz düzeyindedir. En az başarı gösterilen iki soru, \%72.7 oranında doğru yanıt verilen, mantıksal ifadeden devre kuruluma geçiş ile devre şemasından 
mantıksal ifadenin çözümlenmesi ile ilgili olan sorulardır. Mantıksal ifadeden devre kurulumuna geçiş ile ilgili olan soru ise tüm öğrenciler tarafından doğru yanıtlanmıştır. Aşağıda bu mini sınavdaki sorulardan bir örnek verilmiştir.

Örnek soru: Aşağıdaki devrenin ifadesi hangisidir?

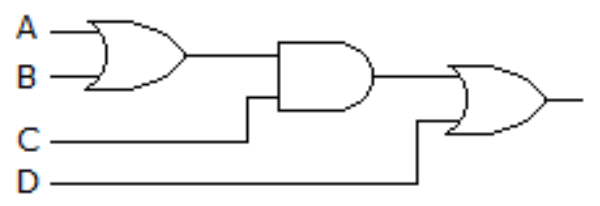

a) $\mathrm{CA}+\mathrm{CB}+\mathrm{CD}$

b) $C(A+B) \bar{D}$

c) $C(A+B)+D$

d) $C A+C B+D$

Dördüncü gün uygulanan mini sınava 31 öğrenci katılmıştır. Öğrencilerin 10 sorunun yaklaşık dokuz tanesini doğru yanıtladıkları görülmüştür. Öğrencilerin en başarısız olduğu sorular sırasıyla, sadece \%67.7 oranında doğru yanıt verilen bir bitlik yarım toplayıcı devresinin giriş bileşenleri ile ilgili olan soru ve \%74.2 oranında doğru yanıt verilen bir bitlik tam toplayıcı devresinin giriş bileşenleriyle ilgili olan sorudur. Toplayıcı devreleriyle ilgili bir genel bilgi sorusu ve bir bitlik bölme devresinin çıkış bileşenleriyle ilgili soru ise tüm öğrenciler tarafından doğru yanıtlanmıştır. Mini sınavlarda genel olarak başarı düzeyi makul düzeyde olup; bu uygulamanın hem işlenen konuların tekrarı açısından, hem de öğleden sonra laboratuvarda uygulama yapılırken devre tasarımında teorik bilginin fiziksel ortama aktarımında faydalı olduğu gözlemlenmiştir.

\section{Sanal Sınıf Geribildirimleri}

Sanal sınıf geribildirimleri öğrencilerin gelişim düzeylerinin gözlemlenmesi ve olası problemlere karşı anlık önlemlerin alınmasında çok faydalı olmuştur. Örneğin; bazı öğrenciler birinci günün sonunda öğle yemeklerinin geç gelmesi konusunda sıkıntılarını dile getirmişlerdir. Bunun çözümü olarak sabah yapılan ilk ders arasında bir liste dolaştırılarak öğle yemeği menüsü tercihleri alınmış ve ikinci ders arasında bu liste restoran yetkililerine iletilerek yemeklerin tam öğle arasında ve herkesin yemeğinin (proje ekibi ile birlikte yaklaşık 40 kişi) aynı anda hazır olması sağlanmıştır. Bu şekilde, yaklaşık 30-45 dakikalık bir zaman tasarrufu sağlanmıştır.

Ayrıca, sanal sınıf oturumlarında, öğrencilerin gün içinde yeterince anlayamadıkları konular ile 
ilgili destekleyici Internet siteleri ve açık kaynak yazılımlar önerilmiştir. Örneğin, basit devre tasarım siteleri ve yazılımlarının adresleri paylaşılmıştır. Ders ve konu özelindeki eleştiriler ve talepler de dikkate alınarak bir sonraki günün teorik ve uygulama çalışmalarında gerekli düzenlemeler yapılmıştır. Örneğin konuların daha fazla örnek soru çözülerek işlenmesi yoluna gidilerek günlük hayattan örnekler de verilerek anlaşılabilirliğin arttırılması hedeflenmiştir. Bu ve benzeri birçok konuda sanal sınıfta alınan geribildirimlerle, bir sonraki günde tespit edilen aksaklıkların önüne geçilmiştir.

\section{Mesleki Eğilim Belirleme Cetveli Sonuçları}

Mesleki eğilim belirleme cetvelini (Mesleki Eğilim Belirleme Cetveli, 2013) cevaplayan 29 öğrencinin ilgili meslek gruplarına eğilim durumu sonuçlarına göre, 29 öğrencinin 18 tanesi, en az bir meslek grubunda 100 ve üzeri puan alarak baskın eğilim göstermiştir. On bir öğrenci ise, herhangi bir mesleki grupta en az 100 puan almayarak, hiç bir mesleki gruba baskın eğilim göstermemiştir. Baskın eğilimi tespit edilen 18 öğrencinin 11'i, Bilgisayar ve Elektrik Elektronik Mühendisliği mesleklerini içeren ve mesleki eğilim belirleme cetvelinde " $\dot{I}$ ” sütunu ile gösterilen kategoriye eğilimlidir. On bir öğrencinin dokuzunda bu meslek kategorisi en yüksek puanı almıştır. $\mathrm{Bu}$ öğrencilerin altısında bu kategori en yüksek puanı alarak ilk sırada yer alırken, üçünde başka bir meslek kategorisi ile eşit puan alarak ilk sırayı paylaşmaktadır. İki öğrenci ise, bu meslek kategorisinde baskın eğilim göstermekle birlikte, başka bir meslek kategorisinde daha yüksek puan alarak daha baskın eğilim göstermektedir. Geri kalan yedi öğrenci ise, Bilgisayar ve Elektrik Elektronik Mühendisliği mesleklerini içeren meslek kategorisinde 100 puanın altında kalarak eğilim göstermeyip, en az bir diğer kategoride 100 puanı geçerek başka bir meslek grubuna baskın eğilim göstermiştir.

\section{Proje Değerlendirme Formu Sonuçları}

Projenin son gününde tüm çalışmalar tamamlandıktan sonra öğrencilere projeyi genel olarak değerlendirmeleri amacıyla proje değerlendirme formları dağıtılmıştır. $\mathrm{Bu}$ formda öğrencilerin teorik dersleri, laboratuvar uygulamalarını, fiziksel koşulları ve projeyle ilgili diğer konuları değerlendirmeleri istenmiştir. Proje değerlendirme formunda bulunan 11 sorunun sonuçlarının ortalaması Tablo 2'de sunulmuştur. Her soru, 1 ile 5 (1 - kesinlikle katılmıyorum, 5 - kesinlikle katılıyorum) arasında olacak şekilde puanlanmıştır.

Tablo 2'deki tüm sonuçların \%80 sınırının üzerinde olduğu görülmektedir. Proje genel olarak değerlendirildiğinde, öğrencilerin genel memnuniyet düzeylerinin yüksek olduğu yorumlanabilir. Özellikle 9. soruya verilen yanıt ortalamasından (en yüksek puan ortalamalı yanıt), projenin 
amaçlarından olan, "öğrencilerin teknolojiye olan ilgi ve merakının artmasını sağlamak", "temel sayısal devrelerin tasarımlarının ve kontrollerinin yapılması konusunda ilgilerini artırmak" ve “elektronik laboratuvarında deney yapmanın ve çalıştırmanın eğlenceli olduğunu göstermek” hedeflerine erişildiği sonucu çıkarsanabilir.

Tablo 2. Proje değerlendirme formu sonuçları

\begin{tabular}{|c|l|c|}
\hline $\mathbf{N o}$ & \multicolumn{1}{|c|}{ Soru Metni } & \multicolumn{1}{|c|}{ Ortalam } \\
\hline $\mathbf{1}$ & Dersler iyi planlanmıştı. & \multicolumn{1}{|c|}{ a } \\
\hline $\mathbf{2}$ & Dersler iyi anlatıldı. & 4,59 \\
\hline $\mathbf{3}$ & Laboratuvar çalışmaları iyi planlanmıştı. & 4,81 \\
\hline $\mathbf{4}$ & Laboratuvarda yapılan konu ve deney anlatımları iyiydi. & 4,78 \\
\hline $\mathbf{5}$ & Laboratuvar malzemeleri yeterliydi. & 4,84 \\
\hline $\mathbf{6}$ & Yemekler yeterli ve doyurucuydu. & 4,78 \\
\hline $\mathbf{7}$ & Diğer etkinlikler (drama, kampüs gezisi, çay molaları) iyi planlanmıştı. & 4,53 \\
\hline $\mathbf{8}$ & $\begin{array}{l}\text { Çalışmalar boyunca bilgisayar donanımının temelleri hakkında bilmediğim } \\
\text { konuları öğrendim. }\end{array}$ & 4,34 \\
\hline $\mathbf{9}$ & $\begin{array}{l}\text { Laboratuvar uygulamaları sırasında temel mantık devreleri üzerinde } \\
\text { çalışmaktan zevk aldım. }\end{array}$ & 4,89 \\
\hline $\mathbf{1 0}$ & $\begin{array}{l}\text { Bilgisayar mühendisliği veya elektronik mühendisliği konusunda bir tercih } \\
\text { yapmayı düşünüyorum. }\end{array}$ & 4,16 \\
\hline $\mathbf{1 1}$ & $\begin{array}{l}\text { Önümüzdeki dönemlerde bu eğitimin devamı niteliğinde temel eğitimlere } \\
\text { devam edilse tekrar katılmayı düşünürüm. }\end{array}$ & 4,50 \\
\hline
\end{tabular}

\section{Genel Değerlendirme Oturumu}

Odak grup görüşmesine ilişkin video çözümlemelerinden elde edilen sonuçlar değerlendirildiğinde, eğitim içeriğinde ve uygulamalarda kullanılan örneklerin günlük hayattan konularla ilgili seçilmesinin konuların kavranmasında faydalı olacağı tespit edilmiştir. Ayrıca, öğrencilere uygulanan tüm soruların çözülmesinin de kavrama açısından aynı düzeyde önemli olduğu görülmüştür. Mini sınavların çözümlerinin projenin son günü topluca değil, sıcağı sıcağına ders sonrası yapılmasının daha verimli olacağı düşünülmektedir. Bunun yanında, konuların daha yüzeysel işlenmesinin ve daha çok ekipmanın tanıtılmasının projenin verimini artırabileceği 
düşünülmektedir. Katılımcı öğrencilerden alınan geribildirimler, aşağıda çeşitli başlıklar altında gruplanarak listelenmiştir.

\section{Projenin gelecek uygulamalarında tekrarlanabilecek olumlu geribildirimler:}

- Tiyatro etkinliği iyiydi, ortama alışmamızı sağladı.

- Girişimcilik semineri faydalıydı, özellikle örnek güzeldi.

- Ders sonunda yapılan mini sınavlar konuyu pekiştirmede faydalı oldu.

- Son gün mini sınavlardaki soruların çözülmesi çok faydalı oldu.

- Taş-kağıt-makas oyunu örneği sayesinde konuyu anladım.

- Ders sunumlarının ve deney föylerinin ders başında dağıtılması faydalıydı.

- Osiloskop kullanımının gösterilmesi çok güzeldi.

\section{Projenin gelecek uygulamalarına yönelik olumsuz geribildirimler:}

- Deney ekipmanları verilseydi evde çalışabilirdik.

- Seminerler uzun ve sıkıcıydı, örneğin meslek seminerleri.

- Güneş altında uzun süre yüründügü için seminerlerde genelde bitkinlik oldu.

- Üniversite yürüyüşünde su almaya gidince yolu şaşıranlar oldu, grupta düzensizlikler vard1.

- Diyot, kondansatör v.b. gibi elektronik ekipmanlar gösterilebilirdi.

- Laboratuvarda ve derste farklı tam-toplayıcı şemaları vardı, 1 devre için 1 şema olmaliydi.

- Devrenin tasarımından ziyade kablo çokluğu zorladı. Daha az kablo gerektiren kapılar seçilmeliydi.

- Devrelerin bilgisayarın neresinde kullanıldığı anlaşılmadı.

\section{Eğitim içeriğine yönelik eleştiriler:}

- Derslerde sıkıcı tekrarlar oldu ve çok uzadı.

- K-harita konusu çok zordu.

- Derslerde kullanılan terimler anlaşılmadı.

- K-harita niçin kullanılır tam anlaşılmadı.

- Konu kapsamı baştan verilmedi.

- Devre optimizasyonu çok basit işlendi, daha ileri teknikler gösterilmeliydi.

- Aritmetik mantık konusundaki derslere daha çok vakit ayrılmalı.

\section{Dikkate alınabilecek diğer tespitler:}


- Konular iyiydi, laboratuvar çalışmaları güzeldi.

- Konuların yavaş ve tane tane anlatılması faydalı oldu.

- Laboratuvarlarda anlatılanları dinlemekten çok kendimiz deneyerek yapmaya çalıştık, ekipmanları kurcalamak hoşumuza gitti.

- Devre tasarımı yazılımları anlatılabilirdi.

- Kuru pastalar bayattı.

- Çay molasında içecek seçenekleri zenginleştirilmeli.

\section{Veli Değerlendirmeleri}

Projenin sonunda, velilere cep telefonu mesajı ve elektronik posta yolu ile ulaşılarak, projeyi ve öğrenciler üzerindeki etkilerini yorumlamaları istenmiş̧ir. Toplam 13 veliden gelen geribildirimlere bakıldığında, projenin öğrencilerin çalışma motivasyonunu arttırdığı ve proje kapsamında öğrencilerde bir mesleki farkındalık oluştuğu çıkarsanabilir. Velilerden alınan geribildirimler aşağıda listelenmiştir.

- Bilgisayar Donanımına Giriş: Kendi Devremi Kuruyorum başlıklı projesinde kızımın yer almasının gururunu yaşatan, ilgi ve desteklerini hiç eksik etmeyen siz ve proje ekibiniz teşekkür eder, başarılarınızın devamını dilerim.

- Sayın hocam, oğlum bu projeye büyük bir hevesle girdi ve çok memnun kaldı. Yeni projeler olursa yine katılmak istiyor. Başta size ve emeği geçen bütün hocalara çok teşekkür ederiz.

- Değerli hocam, oğlum her gün eve geldiğinde yaptıkların heyecanla anlatıyordu. Bu heyecanı ona yaşattığınız, yeni bir meslek ufku açtığınız ve birçok katkı yaptığınız için teşekkürler.

- A.T.C.'nin annesi olarak, size ne kadar teşekkür etsek az. Bu projeyle oğluma yepyeni bir bakış açısı kazandırdığınız gibi vaktini kaliteli bir biçimde öğrenerek ve paylaşarak, düşünerek ve yorum yaparak geçirmesini sağladınız. Şimdi aldığı bu kısa eğitimle ne istediğini bilen kendine daha çok güvenen odaklanması kolaylaşmış bir öğrenciyle karşılaşıtı. Emeklerinize, düşüncenize ve projenize sağllk.

- Merhaba, size ve öğretim ekibinize çok teşekkür ederiz. Kızım İ. kurs boyunca kursunuza devam etti. Mühendislikle ilgili ön bilgisi olsun, meslek seçerken bilinçli olsun istedik. Kursunuz bu konuda çok yardımcı oldu. Mühendisliğe özgü kavramların bir kısmını da öğrenmiş oldu, ufku genişledi. Neyi istediğinin yanında neyi istemediği konusunda da farkındalık yarattı okulunuz (umarım diğer meslekler konulu yaz okulu da yapılır). Adobe Connect aracılı̆̆ıyla yaptığınız akşam eğitiminiz etkileyici ve efektifti. Okulunuzla ilgili 
olumsuz hiçbir düşüncem olmadı. Tekrar teşekkür ederiz. İyi çalışmalar.

- Sayın hocam, projeniz baştan sona kadar mükemmeldi. Oğlum, her gün eve büyük bir mutlulukla geldi. Elektronikle ilgili laboratuvarda çalışması, sanal sınıfta bulunması onun için yeni deneyimlerdi. Özellikle tek başlarına bir şeyler yapmaya çalışmaları onları daha da teşvik etti. Hepinize çok teşekkür ediyorum.

- Sayın hocam, oğlum bir tek cümle ile geçirdiği bir haftayı bize özetledi "hayatımda hiçbir tatilimin bir haftasını bu kadar zevkli geçirmedim”. Eşim ve ben ilginize ve emeğinize çok teşekkür ediyoruz. Saygılarımla.

- Sayın hocam, okuldan gelen maili fark edip yaz okulunuza katılabildiğimiz için şanslı olduğumuzu düşünüyorum. Oğlum çok mutlu oldu. Bu konular, yazılım vb ilgi alanı. Kendi kendine geliştirmeye çalışıyor. Bu çocuklara ilerdeki projelerinizde öncelik tanırsanız çok seviniriz. Emekleriniz için çok teşekkür ederiz.

- Sayın hocalarım, projenize oğlumu da dahil ettiğiniz için çok teşekkür ederim. Projeniz sırasında, Ege Üniversitesi gibi bir kampüs üniversitesinin çeşitli olanaklarını sunduğunuz için de ayrıca teşekkür ederim. Sanal sınıf uygulamasına ben de kenardan katıldım ve büyük bir yenilik olduğunu bana da öğrettiniz. Bir hafta boyunca ailecek hem eğlendik hem de öğrendik. Emeklerinize sağlık.

- Sayın hocam, bir haftalık kurs boyunca çocuklarımıza kattığınız bilgi becerilerden ve açtığınız yeni ufuklardan dolayı size ve tüm değerli hocalarımıza çok teşekkür ederim. Saygı ve sevgilerimle.

- Çok teşekkür ediyorum, ilginize, sabrınıza misafirperverliğinize.

- Biz Y.A.'nın velisiyiz. Vermiş olduğunuz kurstan gerek oğlum gerekse biz memnun kaldık. Mühendisliğe merakı olan oğlum için iyi başlangıç oldu. Kurmuş olduğumuz temasın devam etmesi oğlumun devamlı olarak bilgilendirilmesi ve üniversite sınavına kadar değişik zamanlarda sizler tarafından düzenlenen etkinliklere çağırılması en büyük temennimiz. Şahsınıza teşekkür ederiz...

- Öğrencinin seçeceği mesleği 9.sınıf yaz kampında yaparak ve yaşayarak öğrenmesi bilgi edinmesi çok önemli tecrübedir. Bunun diğer branşlarda da sürdürülmesi tecrübeleri daha da arttıracaktır. Yapılan etkinlik ve içeriğin özenilerek hazırlanması ve öğrencilerimize en uygun koşullarda kazandırılmasında emeği geçen tüm değerli hocalarımıza teşekkür ederiz. A Okulu öğrencimiz M.A.A.'nın velisi olarak teşekkür ediyoruz.

Velilerden gelen geribildirimlerde olumlu geri bildirimler, çocuklarına yönelik yansımalar, ileriye 
yönelik istekler ve teşekkürler öne çıkmaktadır. Öğrencilere dair yansımalara bakıldığında, öğrencilerin motivasyonlarının artması ve mühendislikle ilgili farkındalık kazanımları öne çıkmaktadır.

\section{Gözlemler}

Proje genelindeki gözlemler öğrencilerin tümünün uygulanan farkındalık projesi etkinliklerine istekli olarak katıldıklarını göstermiştir. Ortalama devam oranlarının oldukça yüksek olması da bu gözlemi desteklemektedir. Ayrıca, öğrencilerin laboratuvar etkinliklerini kendi başlarına tamamlama konusunda tatmin edici bir başarı oranına ulaştıkları gözlemlenmiştir.

Mini sınavlardaki \%90'a yakın doğru cevap ortalaması, genel olarak öğrencilerin başarı düzeyinin yüksek olduğunu göstermektedir. Mini sınavlar; hem işlenen konuların tekrarını sağlamak bakımından, hem de öğleden sonraki laboratuvar uygulamalarında devre tasarlarken teorik bilgilerin fiziksel ortama aktarımını kolaylaştırmak bakımından oldukça faydalı olmuştur.

Günlük sanal sınıf oturumları, ilgili güne ilişkin geribildirim alınmasını sağlayarak, olası problemlere sonraki gün müdehale edilmesini sağlamaları bakımından oldukça faydalı olmuştur. Proje değerlendirme formu ve odak grup görüşmesinden elde edilen geribildirimler, öğrencilerin projeden genel memnuniyet düzeyinin oldukça yüksek olduğunu ve mühendislik alanıyla ilgili farkındalık düzeylerinde artış olduğunu göstermektedir. Veli değerlendirmeleri de, bu gözlemleri desteklemekte ve projenin amacına ulaştığını doğrulamaktadır.

\section{Tartışma}

$\mathrm{Bu}$ çalışmada, lise öğrencilerine bilgisayar ve elektronik mühendisliği programlarını tanıtan bir hafta süreli bir uygulamalı mühendislik farkındalık projesinin yapısı ve çıktıları sunulmuştur. Proje 35 onuncu sınıf öğrencisinin katılımıyla başarıyla tamamlanmıştır. Proje teorik dersler, laboratuvar etkinlikleri ve sosyal etkinlikler içermektedir. Dersler sayı sistemleri, Boolean mantık, kap1 düzeyinde sadeleştirme ve temel sayısal devre tasarımı prensipleri gibi kavramlara odaklanmaktadır. Laboratuvar etkinlikleri öğrencilere kendi tasarımlarını uygulamaları ve laboratuvar ortamında aktif olarak uygulamalı deneyim kazanmaları için fırsat sağlamıştır. Yaratıcı drama, tanıtıcı kampüs gezisi, Ege Üniversitesi Bilgisayar Mühendisliği ve Elektronik Mühendisliği Bölümleri'nin tanıtımları ile girişimcilik ve patentlerle ilgili sunumlar ise, proje kapsamında sağlanan sosyal etkinliklerdir.

Mini sınavlar, günlük sanal sınıf uygulamaları, proje değerlendirme formu, genel değerlendirme oturumu (odak grup görüşmesi) ve velilerin geribildirimleri proje çıktılarının değerlendirilmesi için kullanılmıştır. Mini sınavların sonuçları oldukça iyi düzeydedir, öğrenciler projeye duydukları genel 
memnuniyet durumlarını proje değerlendirme formlarında belirtmişlerdir, sanal sınıf oturumları proje çalışanlarının günlük geribildirim almalarını sağlamıştır ve genel değerlendirme oturumu öğrencilere projenin her alanıyla ilgili fikirlerini açıklama fırsatı sunmuştur. Değerlendirme malzemelerinin tümünün analizi göstermektedir ki, öğrenciler yaratıcılığın teşvik edildiği ve teorik bilgileri pratik uygulamaya dönüştürme imkanı sağlanan verimli bir ortamda bilgisayar ve elektronik mühendisliği alanlarının temellerini kavramıştır. Bu bulgular veli geribildirimlerinin analizi ile de desteklenmiştir. $\mathrm{Bu}$ proje sayesinde öğrencilerin motivasyon düzeylerinin ve mühendislikle ilgili farkındalıklarının artması literatürdeki benzer çalışmalarda elde edilen bulgularla paralellik göstermektedir (Mehrizi-Sani, 2012, Smaill, 2010).

Öğrencilerin geribildirimleri bu projenin tekrarı ve hatta daha geniş kapsamlı ve daha uzun süreli geliştirilmiş yeni sürümleri için yüksek talep olduğunu göstermektedir. Teşvik edici bu geribildirimlerin bir sonucu olarak, elde edilen deneyimlerden ve bu çalışma ile kazanılan bilgi birikiminden de faydalanılarak olası tüm geliştirmeleri dikkate alan yeni bir mühendislik farkındalık projesi önerisi Türkiye Bilimsel ve Teknolojik Araştırma Kurumu'na (TÜBİTAK) sunulmuştur.

Tüm bunlara ek olarak, projenin son gününde gerçekleştirilen genel değerlendirme oturumunda öğrencilerden bilgisayar yazılımı alanına yönelik bir mühendislik farkındalık projesi için yoğun bir talep gelmiştir. $\mathrm{Bu}$ talep proje ekibi tarafından değerlendirilmiş olup, yazılım alanı için bir mühendislik farkındalık projesi ileriye yönelik olarak düşünülebilir.

\section{Teşekkür}

$\mathrm{Bu}$ projedeki destekleri için, Türkiye Bilimsel ve Teknolojik Araştırma Kurumu'na (TÜBİTAK proje no 115B284), Ege Üniversitesi, Eğitim Fakültesi, Bilgisayar ve Öğretim Teknolojileri Eğitimi Bölümü'ne, ve Ege Üniversitesi, Mühendislik Fakültesi, Bilgisayar Mühendisliği Bölümü'ne teşekkür ederiz. Bu çalışmada sunulan tüm görüşler, bulgular ve sonuçlar yazarların deneyimlerine dayanmakta olup, ilişkili olan kurumların bakış açılarını yansıtmamaktadır. 


\section{Kaynakça}

Blair, T. B., ve Davis, C. E. (2013). Innovate engineering outreach: A special application of the Xbox 360 Kinect sensor. 2013 IEEE Frontiers in Education Conference (FIE), ss. 1279-1283.

Chan, Y. Y., Hui, D., Dickinson, A. R., Chu, D., Cheng, D. K. W., Cheung, E., Ki, W. H., Lau, W. H., Wong, J., Lo, E. W. C., ve Luk, K. M. (2010). Engineering outreach: A successful initiative with gifted students in science and technology in Hong Kong. IEEE Transactions on Education, 53(1), 158-171.

Cocozza, J. D. (2007). Work in progress-an innovative science and engineering outreach program. 2007 IEEE 37th Annual Frontiers In Education Conference-Global Engineering: Knowledge Without Borders, Opportunities Without Passports, ss. F2B-6.

Egbue, O., Long, S., ve Ng, E. H. (2015). Charge it! Translating electric vehicle research results to engage 7th and 8th grade girls. Journal of Science Education and Technology, 24(5), 663-670.

Gasser, M., Lu, Y. H., ve Koh, C. K. (2010). Outreach project introducing computer engineering to high school students. 2010 IEEE Frontiers in Education Conference (FIE), ss. F2E-1.

Krueger, R. A., ve Casey, M. A. (2002). Designing and conducting focus group interviews. Social Analysis, Selected Tools and Techniques, 4-23. http://www.eiu.edu/ihec/KruegerFocusGroupInterviews.pdf adresinden elde edildi.

Mehrizi-Sani, A. (2012). Everyday electrical engineering: A one-week summer academy course for high school students. IEEE Transactions on Education, 55(4), 488-494.

Mesleki Eğilim Belirleme Cetveli. (2013). Milli Eğitim Bakanlı̆̆ı tarafından önerilen mesleki eğilim belirleme cetveli http://mebk12.meb.gov.tr/meb_iys_dosyalar/41/13/972921/dosyalar/2013_10/28104902_mesle kielmbelirlemetesti.doc adresinden elde edildi.

Molina-Gaudo, P., Baldassarri, S., Villarroya-Gaudo, M., ve Cerezo, E. (2010). Perception and intention in relation to engineering: A gendered study based on a one-day outreach activity. IEEE Transactions on Education, 53(1), 61-70.

Ngai, G., Chan, S. C., Cheung, J. C., ve Lau, W. W. (2010). Deploying a wearable computing platform for computing education. IEEE Transactions on Learning Technologies, 3(1), 45-55.

Oware, E., Capobianco, B., ve Diefes-Dux, H. A. (2007). Young children’s perceptions of engineers before and after a summer engineering outreach course. 2007 IEEE 37th Annual Frontiers In Education Conference-Global Engineering: Knowledge Without Borders, Opportunities Without Passports, ss. S2B-3. 
Roediger III, H. L., Putnam, A. L., ve Smith, M. A. (2011). 1 Ten Benefits of Testing and Their Applications to Educational Practice. Psychology of Learning and Motivation-Advances in Research and Theory, 55, 1.

Smaill, C. R. (2010). The implementation and evaluation of a university-based outreach laboratory program in electrical engineering. IEEE Transactions on Education, 53(1), 12-17.

Thomas, W., Kruse, K., ve Middlebrook, C. (2012). Holography demonstrations and workshops for science and engineering outreach. SPIE Optical Engineering + Applications (International Society for Optics and Photonics), ss. 84810S-84810S.

Watkins, S. E., ve Swift, T. M. (2007). Work in progress-tailoring optics resources for K-5 precollege outreach. 2007 IEEE 37th Annual Frontiers In Education Conference-Global Engineering: Knowledge Without Borders, Opportunities Without Passports, ss. F2B-15. 


\section{Extended Abstract}

Information systems and computers have become pervasive in every aspect of our daily lives especially in the new millennium. Most of the computers work in embedded system manner for controlling wide variety of devices. Embedded systems exist in all of the electronic devices such as refrigerators, satellite receivers, smart phones, printers and so on. The basic design principles of embedded system rely on computer engineering and electronics engineering disciplines. There are many studies underlining the benefits of introducing engineering disciplines to high school students early on instead of delaying it until undergraduate education (Blair and Davis, 2013, Smaill, 2010, Watkins and Swift, 2007). Hence, engineering outreach briefly addresses the studies on improving public expression of engineering which promote graduate level engineering branches and their respective theoretical and technological foundations. The engineering outreach project applied in this study targets Electrical and Computer Engineering (ECE) programs.

Ministry of Education branch in Bornova district has been contacted for choosing students from high schools. As a result, 35 volunteered $10^{\text {th }}$ grade students were selected from 3 different schools with the approval of their high school teachers. The student group participating in this outreach project consisted of 10 girls and 25 boys. Project personnel consisted of 4 academicians experienced on the project concepts. This outreach project has the potential to be applied in more schools nationwide with its functional project costs being less than \$20.

The project consisted of theoretical lectures, laboratory activities and social activities. The lectures focused on concepts such as number systems, Boolean logic, gate-level minimization and basic digital circuit design principles. The laboratory activities gave students the opportunity to apply their designs and gain hands-on experience in a laboratory environment. The social activities provided within the project were creative drama, introductory campus trip and presentations on entrepreneurship and ECE programs of Ege University.

Quizzes, daily virtual classroom sessions, professional tendency detection scale, project evaluation forms, general discussion (focus group interview) session and parents' feedbacks were used for the evaluation of the project outcomes. The evaluation processes were categorized under two main titles below, namely quantitative feedbacks and qualitative feedbacks.

Quantitative feedbacks: 10-question quizzes were applied following the lectures in the morning of the $2^{\text {nd }}, 3^{\text {rd }}$ and $4^{\text {th }}$ days of the project. Multiple-choice questions were evaluated by only the correct answers being counted. Namely, each correct answer were scored as +1 point, where wrong answers and no answers had no effect on total quiz score. The duration for each quiz was 10 minutes. 
Although the questions in those quizzes were on elementary level, considering the inexperience of students on those topics, they provided useful roundup for students right before the experimental applications that will be implemented in the laboratory sessions following the lectures. The overall score of quizzes were satisfactory in general with a score of 8.87 over 10. Thus, it was concluded that the quizzes were useful on both instant lecture review basis and the transfer of theoretical knowledge to physical environment at laboratory sessions.

Qualitative Feedbacks: Daily virtual classroom sessions, professional tendency detection scale, project evaluation forms, general discussion (focus group interview) session and parents' feedbacks were used to get qualitative feedbacks. The students were invited to virtual classroom environment running on Ege University Internet backbone for the evenings of the first 4 days of the outreach project between $7 \mathrm{pm}$ and $8 \mathrm{pm}$. The virtual classroom feedbacks were very useful for resolving different issues as soon as possible in daily activities. Many different online teaching materials and open source software were introduced to students in these sessions for the sake of enhancement support on the theoretical concepts shown during the lectures throughout the day.

The project evaluation forms and general discussion (focus group interview) session were conducted on the last day of the project when all activities had been completed, in order to get overall feedback about the outreach project. The evaluation form consisted of 10 items in a 5-choice Likert style manner to provide evaluation ground for students about the lectures, the laboratory applications, the physical environment and many other details about the project as a whole. The overall results of the project evaluation form indicated high satisfaction level of students on many occasions.

After the completion of project evaluation forms, a general discussion (focus group interview) session was conducted with the participation of all students and the project personnel, in order to get open feedbacks from each and every student in an open interactive discussion environment. The general discussion session took 75 minutes and all discussions were recorded (video-taped) for future analysis. The analysis on the records indicated that all lecture materials and experimental applications must be supported with more practical and fun real-life examples for this age group in order to promote better understanding of concepts. The students also underlined the utility of lecturer's solving all quiz problems, and it was concluded that it could have been even more useful if solutions of quiz questions had been discussed right after each quiz. They also stated that theoretical lectures could be reduced to introduce more electric equipment to students by adding more laboratory hours. 
The parents' opinions were gathered as the last qualitative feedback. The parents were contacted via SMS and e-mails and they were asked to evaluate this outreach project in an open-ended fashion. The available feedbacks from parents were analyzed on different aspects of the project and showed positive results about the students' motivation levels.

The overall analysis of the evaluation materials showed that students have developed some insight about computer and electronics engineering in a friendly atmosphere promoting creativity and proper practical application of theoretical knowledge. These findings also were supported by the analysis on parents’ open-ended feedbacks. 